\title{
PARA SAIR DO ENTRE-DUAS-LÍNGUAS: A TRADUÇÃO COMO PRÁTICA DE DESCONFINAMENTO'
}

\author{
TO GET OUT OF THE (IN-)BETWEEN-TWO-LANGUAGES: \\ TRANSLATION AS A PRACTICE OF DECONFINEMENT
}

\section{Marie-Lou Lery-Lachaume*}

\section{RESUMO}

Em 1988, Derrida formulava um enunciado programático para os filósofos, jubilatório para os tradutores: "Plus d'une langue!". Este artigo parte de uma retomada da palavra de ordem derridiana, uma re-petição que permite esgueirar-se para um pensamento vivo, intimamente ligado a uma aposta da tradução. Depois de dar a essa aposta seu alcance amplo, busca-se examinar como, em cada língua, o "Plus d'une langue" funciona como agenciação-desconstrução, isto é, como operação imanente e intensiva de tradução infralinguística. Ora, se essa multiplicidade interna às línguas como redes idiomáticas aponta para um potencial de transmissão "aquém" do encontro entre duas línguas, é esse encontro entre as línguas como singularidades idiomáticas que define tradicionalmente a prática da tradução como transformadora e, eventualmente, trânsfuga. Nessa perspectiva, o avesso da reflexão proposta releva o paradigma da tradução como circulação entre-duas-línguas, para problematizá-lo e avaliar a possibilidade de ultrapassálo. Para além da topologia do entre, e se houver mais de duas línguas, traduzir é ainda concebível? Isso implica uma tentativa de forçagem e, talvez, de oxigenação das teorias da tradução historicamente confinadas pela Linguística. O resultado desse esforço, ele próprio guiado pela radicalização final da lógica do "Plus d'une langue" mediante um "Encore plus de langues", é uma interrogação sobre a tradução como onda de choque translinguística e sobre o escândalo do ato do tradutor. O que sobra da arte da tradução quando o tradutor "cai fora" do sagrado pacto de tradução e recusa, na ausência patenteada de relação, qualquer reciprocidade entre as línguas?

Palavras-chave: tradução; desconstrução; multilinguismo; crioulização; transtradução.

\section{ABSTRACT}

In 1988, Derrida formulated a programmatic statement for philosophers, which is a jubilatory encouragement for translators: "Plus d'une langue!". This paper starts from a resumption of the Derridian watchword, a re-petition that makes us gest inside a living thought, intimately linked to a challenge of translation. After giving this challenge its more extended reach, we seek to examine how, in each language, the mechanism of "Plus d'une langue" works as agenciation-deconstruction, that is, as an immanent and intensive operation of infralinguistic translation. Yet, if this internal multiplicity of languages as idiomatic networks points to a potential of transmission "below" the encounter between two

\footnotetext{
* Universidade Estadual de Campinas, Unicamp, Campinas, SP, Brasil. marieloulerylachaume@yahoo.fr Orcid: https://orcid.org/0000-0002-1798-3360

1. Agradeço a Viviane Veras e a Maria Angélica Deângeli pelas leituras finas e os apontamentos preciosos, que contribuíram para o movimento de desconfinamento almejado neste artigo.
} 
languages, it is this encounter between languages as idiomatic singularities that traditionally defines the translation as transformative and, eventually, transgressive practice. Based on such outlook, the flip side of this reflection focuses on the paradigm of the translation as a circulation between two languages, to problematize it and evaluate if it would be possible to go beyond it. Overcoming the topology of the between, and with more than two languages, is translating still conceivable? This means attempting to force and, perhaps, to oxygenate translation theories, historically confined by Linguistics. The result of this effort, which is finally guided by the radicalization of the logic of "Plus d'une langue" through an "Encore plus de langues", is an inquiry about translation as a translinguistic shockwave, and about the scandal of the translator's act. What remains of the art of translation when the translator "fucks off", getting out of the sacred pact of translation and refusing, for a patent lack of relationship, any reciprocity between languages?

Keywords: translation; deconstruction; multilingualism; creolization; transtranslation.

From the Bible to the Coran

Revelation in Jerusalem

Shalom, salamalekoum

You can see Christians, Jews and Muslims

Living together and praying

Amen, let's gives thanks and praises

Barouh atat adonai

Barouh atat yroushalaim

Barouh atat adonai

Barouh atat yroushalaim

Jerusalem here I am

Jerusalem je t'aime

Jerusalem here I am

Jerusalem je t'aime

Alpha Blondy, bardo reggae, Jérusalem ${ }^{2}$

\section{INTRODUÇÃO}

A reflexão desenvolvida neste artigo nasce em um contexto especial, o da pandemia de coronavírus, com suas implicações político-sociais e linguísticas que vão da necessidade de isolamento físico - também chamada de "confinamento" - à recorrência, em diversas línguas, de um mesmo significante que ressoa tristemente, como uma sina insuportável: "Covid19". Ainda que inserido em uma tal conjuntura e afetado por circunstâncias inéditas, este trabalho não visa abordar a especificidade da prática da tradução em tempos de confinamento, assim como não se propõe a estudar as modalidades e escolhas de traduções da terminologia relacionada à Covid19. Pretende, antes, amparar-se em um pensamento do confinamento mais

2. Quando "hereIam" rimacom "Jet'aime" ${ }^{\prime}$ escutem: https://www.youtube.com/watch?v=WcqK9Ls7Eos 
inatual e intempestivo (unzeitgemäss, como escrevia Nietzsche), sustentado pela nossa condição de falantes e pelo fato de que bá línguas - não somente línguas múltiplas, mas, sobretudo, uma diversidade irredutível das línguas -, a fim de considerar o desconfinamento na perspectiva e a partir da prática da tradução. Trata-se de abrir uma brecha e, nela, engajar-se a fundo.

Nessa brecha, porém, não vamos nos precipitar. Pois a especificação do que podemos chamar, transitoriamente, de confinamento "linguístico" ou "idiomático" não é nada simples. Além disso, o impulso endógeno do gesto do tradutor, apesar de bastante intuitivo, deve ser problematizado logo de início, para que possamos trabalhar com uma topologia da tradução - seus pontos de ancoragem, resistência e (im)passes - válida e operatória. À primeira vista, é verdade que a tradução parece antinômica a qualquer ideia ou cenário de confinamento. Seja ela vista como um convite à viagem, uma ponte, a saída de si pela mão estendida em direção ao Outro ou, quando focada no que acontece à margem do seu próprio processo, como experiência mais incerta de deslocamento no limiar, isto é, de acordo com a distinção apontada por Alexis Nouss (2012); seja ela concebida como passagem de uma língua à outra (tendência ao cinecentrismo) ou como passagem de uma na outra (exploração de uma zona paratraducional), as diversas referências que permitem pensar a tradução supõem, no mínimo, movimentação e aproximação. Sem falar da metáfora do enxerto - inserção, penetração e geração de uma terceira entidade -, vale lembrar que, na sua versão, digamos, mais erotizada, o modelo da tradução é a abolição do distanciamento e a reivindicação do contato físico. Traduzir remete, nesse caso, à experiência ardente e impetuosa de um corpo-a-corpo. Quando não competem, as línguas se achegam e se aconchegam, acariciam e aquecem-se; no ápice, podem até mesmo se chupar (o que é, aliás, que duas línguas podem fazer melhor?).

De forma surpreendente, porém, o mesmo Derrida que, em Qu'est-ce qu'une traduction "relevante", cunha essa belíssima metáfora da língua que, em tradução, aflora e lambe (lèche) outra língua, refere-se, em "Des tours de Babel", à tradução como forma de confinamento. Mais precisamente, Derrida assinala que, no famoso prefácio de Benjamin, a tarefa do tradutor fica "confinada no duelo [duel] das línguas" (DERRIDA, 1998 [1987], p.230), sendo a dificuldade de considerar "a possibilidade de as línguas de serem implicadas, a mais de duas, em um texto" uma limitação característica das teorias da tradução. Entendamos bem: o problema, aqui, diz respeito a um confinamento das teorias, se não dos tradutores, resistentes a encarrar a eventualidade de uma tradução com mais de duas línguas abarcadas na singularidade do encontro. Se quisermos salientar a radicalidade da tradução, devemos, portanto, desprender-nos da necessidade de representá-la nos termos 
dos paradigmas tradicionais, e pôr em causa não o confinamento em - que ela, por definição, proscreve - mas sim um confinamento entre. É essa inquietante zona do entre-duas-línguas que está em jogo no presente texto, no qual interrogamos a possibilidade, ou não, de pensar a tradução para além dela.

Assim, ao alternar os pontos de vista para avançar aos confins do entre-duaslínguas, este artigo empenha-se na forçagem de um limite das teorias da tradução, tentando, ao mesmo tempo, sair do limbo do entre e buscando dessacralizar a estrutura do Dois, que prevalece quando falamos do duelo, do acoplamento ou, ainda, de um casamento das línguas. Esboçamos, em suma, uma abordagem da tradução como prática de desconfinamento norteada por duas perguntas:

1. se trabalharmos com a hipótese de um desconfinamento da tradução, será que a tradução efetivamente desconfinada é, ainda, tradução, ou essa libertação da tradução chancela sua autoanulação? Em outras palavras, as que Derrida nos deixou, en passant, à guisa de provocação, "Et si l'on traduit par plusieurs langues à la fois, appellera-t-on cela traduire ?" (DERRIDA, 1998, p. 208) "E se traduzimos por várias línguas ao mesmo tempo, chamaremos a isso traduzir?" ${ }^{13}$

2. talvez mais profícuo ainda, se considerarmos a possibilidade de um desconfinamento pela tradução, como apreender o estatuto e as implicações do traduzir como energia desconfinante?

Mais de uma lingua ("Plus d'une langue"), mas nunca mais de duas? ("jamais plus de deux?"). E por que não? Que tal juntar muitas línguas, um monte de línguas até ficar cheios, saturados e - why not? - abastecidos de linguas? "Faire le plein" de langues, com cada vez mais línguas (toujours plus de langues)...

Borá lá!

\section{1. "PLUS D'UNE LANGUE !" TRADUTTORE, DECOSTRUTTORE...}

\subsection{Mutatis mutandis - a figura do tradutor-desconstrutor}

Começamos com aquilo que constitui não uma teoria derridiana da tradução - essa, se existisse de alguma forma, não se deixaria amuralhar nem encaixilhar em palavras sobre ela -, mas sim com a retomada de uma ousadia de Derrida, articulada

3. Todas as citações oriundas de um texto inicialmente em francês serão ora deixadas em francês, mas comentadas por mim em português, ora traduzidas para o português. As traduções são, no caso, de minha autoria. 
sob a forma de uma palavra de ordem: "plus d'une langue". Qual a ressonância, hoje em dia, do surgimento desse jato de quatro palavras há mais de três décadas? E em que medida é possível dizer que, nesse bocado de frase a-sintático que virou lema, tradutor e desconstrutor se confundem na figura rebelde e fecunda de um agitador de pensamento?

Uma literatura consequente já foi produzida a respeito das ligações entre Desconstrução e Tradução, e não entraremos, aqui, nos pormenores dessa discussão. Lembremos tão somente que a conjunção das duas ou, melhor, a Tradução como via régia para a Desconstrução, trabalha, como é sabido, em prol da renovação dos modos de filosofar, conferindo à Tradução um valor eminentemente filosofante. Um exemplo magistral e empolgante disso é o Vocabulaire européen des pbilosopbies ideado e dirigido por Barbara Cassin, e mais conhecido por seu subtítulo Le Dictionnaire des intraduisibles. Esse dicionário, particularmente barroco, traduzido em várias línguas na sequência da sua primeira publicação, aposta na filosofia no plural: as filosofias. Filosofar com os intraduzíveis, nesse sentido, revela um posicionamento duplo: "Nem universalismo lógico indiferente às línguas, nem nacionalismo ontológico com essencialização do gênio das línguas" (CASSIN, 2019, "Apresentação", p. $\mathrm{XX)}$, trata-se, na esteira do Derrida de "Plus d'une langue!", de partir do múltiplo para nele permanecer e demorar.

Esse posicionamento bastante característico da figura do tradutordesconstrutor (que tomo, aqui, como ponto de partida) produz, em primeiro lugar, um ganho filosófico, uma vez que, se não existem conceitos sem palavras, então o trabalho de pensar a partir dos intraduzíveis - isto é, no fundo, o trabalho de traduzir - sempre deixa alterada a conceitualidade que lavra, tornando o leitor do dicionário "sensível a essas distorções e a esses fluxos semânticos" (CASSIN, 2019, p. XXI). Minuciosamente, determinadamente, autores do dicionário dos intraduzíveis ${ }^{5}$ traduzem, transformando as ambivalências semânticas em desafio pelo pensamento e elevando o equívoco ao estatuto de problema filosófico a ser ruminado pelo leitor. Um exemplo, entre tantas outras pérolas que os filósofos encontram quando

4. Em contexto (em Mémoires pour Paul de Man):"Si j'avais à risquer, Dieu m'en garde, une seule définition de la déconstruction, brève, elliptique, économique comme un mot d'ordre, je dirais sans pbrase: "plus d'une langue "" (DERRIDA, 1988, p. 38 - "Se tivesse que arriscar, Deus me livre, uma única definição da desconstrução, breve, elíptica, económica como uma palavra de ordem, diria sem frase: "mais de uma lingua""). Caracteristicamente, foi pela negação e, em rigor, pela denegação da possibilidade de definir a empreitada da Desconstrução associada à sua obra filosófica que Derrida, descontruindo a própria noção de definição, forjou a fórmula notória que retomamos e pretendemos radicalizar neste trabalho.

5. Lembrando que um "intraduzível", nessa ótica, não é aquilo que não pode ser traduzido, mas "aquilo que não cessa de não ser traduzido" (CASSIN, 2019, p. XVII). 
entram no jogo da tradução ${ }^{6}$ o verbete "mir" (Dictionnaire des intraduisibles, p. 803808), que significa, em russo, "paz" e "mundo". A mera indicação dessa homonímia pelo tradutor coloca-o diante de um conjunto de perguntas: mir-paz e mir-mundo sempre foram termos etimologicamente distintos? Ou um desses dois semantismos deriva do outro? $\mathrm{Ou}$, ainda, a partir de uma noção comum, é preciso imaginar duas derivações possíveis? Essas perguntas, que não necessariamente serão respondidas, levam à construção de um problema de alto teor filosófico: em torno da intersecção - essencial ou arbitrária? - entre os campos do mundo e da paz, noções filosóficas como cosmos e concórdia; comunidade, sociedade e história surgem. Se o filósofo, querendo ou não, é sempre tradutor de textos, conceitos e pensamentos que o precedem, o tradutor, por sua parte, é interpelado enquanto filósofo. A esse respeito, a tradução do Dictionnaire des intraduisibles não representa nenhuma contradição, mas potencializa o gesto inicial, como notavelmente demonstrado em Philosopher en langues - Les intraduisibles en traduction (dir. CASSIN, 2014).

\subsection{In varietate concordia - o fazer-político dos tradutores}

"Plus d'une langue!" Em "mais de uma língua", portanto, os tradutoresdesconstrutores filosofam. Isso posto, é fundamental afirmar que o efeito filosofante não basta para dar conta da radicalidade do seu gesto, que remeti a uma agitação que tem também o sentido de uma rebeldia. Ainda com Barbara Cassin, podemos qualificar esse gesto "sem clausura, muito mais borgesiano ou oulipiano que destinal e heideggeriano" (CASSIN, 2016, p. 54) de gesto político. Como efeito, para quem leva a sério a ideia de diversidade das línguas "compreendida como uma pluralidade diferencial de performances" (p. 54), a questão das condições e das modalidades do viver-juntos apresenta-se de forma especial. De novo, a dupla recusa em forma de "nem ... nem..." assinala, mais positivamente, a reinvindicação de um mundo habitável: "nem todo-para-o-inglês", e até mesmo, "nem sistema de inglesgotos" o "tout-à-l'anglais", em francês, ressoando com o "tout-à-l'égout" (o saneamento básico) -, "nem nacionalismo ontológico" (CASSIN, 2016, p. 55), mas sim afirmação da tradução como língua possível... e como desejo de um fazer-comunidade irredutível ao torpor do como um.

O tradutor-desconstrutor, nesse sentido, é rebelde à linguagem única da mundialização capitalista em "global english" (ou "globish") que, a coberto do pragmatismo, esvazia as línguas de sua medula de cultura (começando pela língua inglesa), mas também

6. Para levar a cabo a tarefa hercúlea de escrita do Dictionnaire des intraduisibles, cento e cinquenta autores - todos ao menos bilíngues - juntaram suas forças. 
resiste à tentação do encerramento idiomático-identitário que, com base numa sacralização do Intraduzível, tende a legitimar uma impermeabilidade hierárquica entre as línguas. O enfoque do Dictionnaire des intraduisibles, por ser esse um Vocabulaire européen des pbilosophies, diz respeito à invenção de uma Europa linguístico-filosófica. No entanto, essa dinâmica projetiva, bem como a dupla recusa acima desenvolvida funcionam também fora do seu quadro inicialmente europeu-focado, para não dizer, europeu-centrado. $\mathrm{O}$ interesse dos leitores e a empolgação pela sua tradução em cerca de dez línguas ratificam isso, fazendo vislumbrar, muito além das paragens europeias, outros e múltiplos horizontes políticos que a "frequentação-tradução" dos intraduzíveis, ao mesmo tempo, supõe como ideal e convoca a realizar. Cabe notar, a este respeito, que a sequência título-subtítulo do Vocabulaire européen des philosopbies. Le dictionnaire des intraduisibles uma vez traduzido para o português do Brasil transforma-se, evidenciando a lógica de descentramento e, porque não dizer, uma força descolonizante característica da tradução: "européen" cai e lemos, agora, o Dicionário dos intraduzíveis. Um vocabulário das filosofias.

"Plus d'une langue"... Recordando, mais uma vez, as palavras de Derrida, podemos, então, escutá-las como a expressão de certa insubordinação. Um levante, cuja dimensão indissociavelmente político-linguística é escancarada no movimento da tradução como desconstrução. De fato, ao dar ao "plus" seu valor gramatical de negação - da mesma forma que se proclamaria um "Plus de ça", ou "Plus jamais ça" -, "Plus d'une langue!" quase grita: "Nunca mais uma língua". "Nunca mais uma língua só", a saber, nunca mais a língua única dos imperialismos que chancelam seu universal próprio. E ainda, uma exasperação: "basta com uma língua", isto é, retomando aqui a brilhante expressão de Cassin em seu Éloge de la traduction, não aguentamos mais os "desesperantos contemporâneos" (CASSIN, 2016, p.58), esses tristes empenhos que almejam reduzir as línguas a uma ferramenta de comunicação (a so cost-effective business tool!) desprovida de multiplicidade interna e purgada da dimensão do equívoco.

\section{PLUS D'UNE LANGUE... DANS LA LANGUE ? A MULTIPLICIDADE AQUÉM DO ENTRE-LÍNGUAS: ALGUNS APONTAMENTOS SOBRE 0 ENTE DO MONOLINGUE}

\subsection{Fora do ente : a inquietação da tradução}

"Plus d'une langue!"... Se a multiplicidade como bússola convoca o tradutor a atuar como desconstrutor, pelo menos no sentido filosofante e militante que 
acabamos de dar ao adjetivo, ela lhe diz respeito, também, a título mais íntimo, para não dizer essencial. Envolvido na multiplicidade pelo simples fato de falar na sua língua (ou naquilo que ele acredita ser essa língua), o tradutor, antes de qualquer tomada de posição e como que de antemão, é tomado pela língua enquanto situação, ou estado, ou condição... Algo dificilmente definível, ainda mais na medida em que, como bem pode constatar qualquer um que faz uso dela, soltando a mandíbula para falar, "[1]íngua é uma coisa engraçada. Se, por um lado, em geral nascemos com uma dentro da boca, é só depois de um tempo razoável que começamos a tirar maiores consequências desse órgão tão faceiro e peculiar" (LEITE e SOUZA Jr., 2020, artigo no prelo). O termo escolhido por Derrida para debruçar-se, à sua maneira, sobre essa dificuldade e tirar maiores consequências do seu próprio órgãoelemento, esse termo aparentemente contraditório, é "monolinguismo do outro"7.

"Monolinguismo", em primeiro lugar, na sua acepção derridiana e em relação às categorias linguísticas: lar-língua ou "elemento" em que permaneço e demoro, sentindo que moro. Um "meio absoluto", escreve ainda Derrida no início de Le Monolinguisme de l'autre; descrito "inultrapassável e incontestável". Incontestável e, no entanto, contestado o tempo todo, visto que a espécie de drama filosófico teatralizado no livro se dá como um esforço de cada página para desprender-se dele. Um movimento inicial e inaugural de desconfinamento, bastante paradoxal na sua essência, posto que o monolinguismo como "solipsismo inesgotável" e vivência de isolamento radical configura, de acordo com a interpretação que proponho das palavras de Derrida, uma quarentena contínua e infindável: a eternidade em quarentena; "à demeure" (DERRIDA, 2016 [1996], p14). Nesse contexto, se "esse monolinguismo, para mim, sou eu", e se sua "onipresença em mim", imperiosa e constitutiva, "me prescreve, também, uma solidão monacal, como se alguns votos me houvessem atado, antes mesmo que aprendesse a falar" (DERRIDA, 2016 [1996], p.14, grifo meu), o elã do "plus d'une langue!" tem, rigorosamente, o sentido de uma saída desse solipsismo linguístico. Podemos chamar essa saída, em português e com ressonâncias de ontologia filosófica, de "fora do ente do monolíngue"; o ente do monolíngue caracterizando a situação hipotética do estar-aí de um ser falante que seria confortavelmente condicionado por uma língua só, uma única língua indivisa e contendo-o sem risco de transbordamento.

\footnotetext{
7. O termo foi inicialmente evocado em 1992 em uma palestra que foi retrabalhada e ampliada, na forma escrita, em Le Monolinguisme de l'autre (1996). Interessante lembrar que a primeira exposição dessa famosa meditação foi, portanto, inicialmente falada, quando de um simpósio internacional e bilíngue intitulado "Echoes from Elsewhere/Renvois d'ailleurs". Nessas condições, entendemos que a gênese da reflexão sobre o monolinguismo só podia ser do outro, para não dizer, de albures - em todos os sentidos do genitivo gramatical.
} 
Agora, vejamos bem o tamanho do paradoxo. Enquanto quadro quase transcendental, certeza pré-empírica ou ante-subjetiva do "moi avant moi" (do "eu antes de mim"; a não ser que seja, antes, um "mim antes de eu"?) e, ao mesmo tempo, intuição corriqueira de "moi-même" (de "mim mesmo"; sem que seja necessariamente "eu mesmo" que intui propriamente aí), tudo indica que o monolinguismo sempre me precede, me compõe e me institui como sujeito falante ${ }^{8}$. Não obstante, já no título dado por Derrida a seu livro, esse monolinguismo parece, paradoxalmente, convocado a ser ultrapassado: se existir monolinguismo, ele só poderá ser monolinguismo do outro. Como entender isso? Antes de esboçar uma resposta, notamos que, em tal perspectiva, a tradução enquanto prática por excelência do "mais de uma língua" deve desempenhar um papel fundamental. Eis o sentido da recorrência do tema da tradução em Derrida, mas, também, de suas proezas como tradutor-desconstrutor ao longo do seu percurso filosófico. E não é à toa, aliás, que a tradução surge, em um contexto particularmente crítico e como inquietação, nas primeiras páginas de Le Monolinguisme de l'autre. No momento em que se encontra formulada a "contradição performativa" do falante que, assumindo a antinomia derridiana, afirma simultaneamente ser monolíngue e falar uma língua que não é dele, repentinamente, o interlocutor fictício pergunta:

(à qui parlons-nous, d'ailleurs, pour qui? Et nous traduira-t-on jamais?)

(a quem estamos falando, aliás, para quem? E será que seremos, um dia, traduzidos?). (DERRIDA, p.16, grifo meu)

Essa indagação, colocada entre parêntesis, traz a tradução como inquietação no cerne das aporias e circunvoluções a respeito dessa "língua minha" que nunca é rigorosamente minha. A tradução, portanto, assombra o ente do monolíngue acima definido e, desse modo, impõe uma saída para fora do ente. Fora do ente e, arriscando um trocadilho bastante feliz em francês, bors de l'antre. Pois a simples pergunta visando a possibilidade de essa fala textualizada ser um dia lida e escutada introduz, conjuntamente, um lugar de endereçamento, lugar em que o diálogo do monolíngue poderia ressoar. A bem da verdade, vemos que o outro já está presente, minimamente, como suposição, hipótese ou projeção ("para quem?"). E, com a segunda pergunta abrindo o texto para a eventualidade da sua tradução futura, esse outro já suposto à fala pode ser, ainda por cima, um falante de outra língua.

8. Adentrando o campo da teoria psicanalítica e, em especial, a sequência do ensino de Jacques Lacan, seria interessante recorrer à noção de "falasser" para clivar um pouco mais o monolíngue derridiano. 
Em suma, o ente do monolíngue é, fundamentalmente, ameaçado de divisão pelo mero fato da endereçabilidade da sua fala a (um outro), e o monolinguismo "puro" aparece como ilusão ou, mais exatamente, como fantasia do regresso à origem linguística e à unidade idiomática representada pelo antro psicologista de um monolinguismo do "moi-même" sem chance de tradução.

Fantasia a atravessar e, ou, talvez, a-traduzir?

\subsection{Sair doente do monolinguismo: assombração e tradução}

- On ne parle jamais qu'une langue... (oui mais)

- On ne parle jamais une seule langue...,

- Falamos somente uma língua... (sim, mas)

- Nunca falamos uma língua..., (DERRIDA, 2016 [1996], p.25)

ce n'est pas seulement la loi-même de ce qu'on appelle la traduction. Ce serait la loi elle-même comme traduction.

Não é apenas a própria lei do que se chama a tradução. Seria a própria lei como tradução. (DERRIDA, 2016 [1996], p.25)

"Aposta da tradução", avançava eu logo no início desta reflexão aberta pelo "Plus d'une langue" de Derrida. Aqui, com essa articulação propositalmente contraditória e aparentemente absurda, teríamos uma nuance, remetendo não somente à lei "da tradução", mas também à lei "como tradução"; uma norma geral, quase objetiva, que se apresenta ao falante como uma imposição. Ou seja, se a tradução tem sua lei, ou suas leis (que os tradutores instauram e que as diversas teorias linguísticas da tradução decifram e tentam estabelecer), Derrida nos convida a considerar uma homologia entre tradução e lei. A tradução feita lei, fazendo lei; a tradução e a lei radicadas em uma só necessidade. Uma lei "um pouco louca", acrescente, "como a língua", aliás, "o único lugar e a primeira condição da loucura" (DERRIDA, 2016 [1996], p. 25). Antes de analisar essa referência à loucura, aproveito a perplexidade suscitada pela afirmação de Derrida, e pergunto: sair do ente do monolinguismo levaria, portanto, a sair "um pouco" doente, no sentido de um pouco demente? Em certa medida, sim, pois se é verdade que há algo, na língua, que não bate totalmente bem; se, nela, alguma coisa faz barulho, fala e falha, badala e causa ao mesmo tempo, então, conforme não podemos mais ignorar desde Freud, esse não bater bem da língua recai invariavelmente em quem recorre a ela. Na língua, "ça cloche", podemos dizer com Lacan 
$(1964)^{9}$, e os seres que falam não podem ser senão in-quietos e "um pouco loucos" também; cada falante modalizando esse gap à sua maneira, com sua voz e suas palavras próprias.

Ademais, é importante lembrar que essa coisa que manca, desanda e faz ruído nos interstícios da língua é a mesma coisa que permite que seja sustentada a dupla postulação do monolinguismo e de sua impossibilidade, uma vez que essa só pode ser formulada pela via da anfibologia semântica característica da pseudopremissa acima citada: "On ne parle jamais qu'une langue..." $\Leftrightarrow$ "fala-se, sempre, apenas uma língua" e, indissociavelmente, "nunca se fala apenas uma língua". Ora, justamente por essa razão - razão totalmente antiaristotélica e fundamentada em um fato de estrutura que vamos abordar no segundo tempo deste artigo -, sair um pouco doente de uma língua da qual não podemos sair, isto é, submeter-se à lei da tradução, é a via régia para a grande saúde do falante. A via para um solipsismo absolutamente original, cuja modalidade paradoxal pode ser expressa pela conjunção de duas afirmações que merece ser enfatizada:

"Só se pode falar uma língua nesta língua. Nem que seja colocando-a fora dela-mesma" (DERRIDA, 2016 [1996], p. 43, grifo meu).

Nesta altura, longe do solipsismo da substância pensante que um Descartes, nas Meditações metafísicas, acabava resolvendo em Deus ${ }^{10}$, descobrimos que o solipsismo do falante é fundamentalmente imanente e dinâmico, na medida em que se ampara em um movimento intrínseco à língua. Como uma convulsão raivosa de si mesma, a língua se torna, a cada momento, ela-mesma e exterior a si-mesma. Destarte, poderíamos dizer que a língua é, por essência, paradoxal, (topo)logicamente "inconfinada", inconformada com qualquer lógica de confinamento. E vislumbramos, de maneira ainda mais nítida, a função primordial da tradução nessa lógica: a tradução como certeza incondicional do falante $e$, portanto, motor legítimo e eficaz da empreitada de desconstrução dos modos de filosofar tradicionais. Assim, entendemos igualmente por que, logo depois de definir ou deixar (em) aberto esse

9. A citação exata é a seguinte : « Là, en somme, il y a un trouet queldue chose qui vient osciller dans l'intervalle. Il n'y a de cause que de ce qui cloche. Entre la cause et ce qu' elle affecte, il y a toujours la clocherie ». Cf. lição do 22 de janeiro de 1964 no Seminário XI, em que Lacan retorna aos "fundamentos da psicanálise".

Vale notar que é com essa base de "clocherie" que Mario Laranjeira (2012) desenvolve seu trabalho versando sobre a tradução poética. Essa, em última instância, não faz senão escancarar uma distinção que poderia valer para qualquer trabalho de tradução, entre o registro do sentido e o da significância (ordem da "di-mensão", diria Lacan).

10. Sem pormenorizar, lembro a lógica que, basicamente, é a seguinte: será que existe realmente outra coisa além do meu "eu" pensante e consciente? - sim, porque, caso contrário, Deus me enganaria, e isso não é possível porque é contrário à essência e perfeição divina. 
novo solipsismo que caracterizamos como solipsismo "do falante" em contraste com o solipsismo cartesiano "do pensante" ou "do cogitante", Derrida acrescenta as seguintes palavras:

Impossibilidade de uma metalinguagem absoluta, pelo menos, pois efeitos de metalinguagem, efeitos ou fenômenos relativos, a saber, revezamentos [relais] de metalinguagem "em" uma língua já introduzem, nela, tradução, objetivação em curso. Deixam estremecer no horizonte, visível e milagroso, espectral, mas infinitamente desejável, a miragem de outra língua.

(DERRIDA, 2016 [1996], p. 44)

Vê-se que a tese esboçada aqui é particularmente forte, já que aquilo que está sendo relativizado por Derrida é nada menos que a famosa tese wittgensteiniana da impossibilidade de uma metalinguagem; tese retomada e radicalizada por Lacan que, entre outros pensadores da heterogênea galáxia dos estruturalistas, enunciou a inexistência da metalinguagem. Essa afirmação, mais especificamente, encontrase aí redeclarada e retificada, e a inflexão diz respeito a um tipo de retorno do recalcado da língua na língua: isso traduz; traduz-se.

Mas que tradução é essa? Nas palavras de Derrida, palavras hesitantes de um monolíngue que explora suas aporias às escuras e busca tatear os limites da sua condição, entendemos que o monolinguismo do outro significa, ainda, um monolinguismo assombrado, ou seja, um monolinguismo atravessado pela tradução como operação inerente e, em certa medida, inquietantemente familiar ${ }^{11}$; enfim, e sobretudo, como regime ordinário e ineliminável da língua. Não nos enganamos, porém, quanto à relativização aventada por Derrida. Ele nunca tampouco diz que existe a metalinguagem, e talvez coubesse pensar o trecho citado anteriormente em termos de metalíngua, em vez de metalinguagem. Seja como for, é importante entender que a proposta não é sair da linguagem (ou da língua, digamos, "monolinguada") para falar sobre ela, a respeito e acima dela. Apontando, antes, para dentro, para o isso aí dentro da língua, o filósofo registra a efetividade patente de fenômenos intralinguísticos de transmissão das operações da fala, reconhecidos como "revezamentos" [relais] metalinguageiros.

\subsection{Língua, traduz-ente!}

Revezar, transmitir, substituir, veicular... Como se se tratasse - interpreto eu - de passar o bastão quando de uma mesma corrida desenfreada, ora pela

11. Seria interessante desenvolver essa concepção da tradução em relação com o espectro, voltando a diversas características do espectro em Derrida; longe de ilusório ou irreal, o "spectre" remete à dimensão do luto, à da voz, e à do trabalho. 
significação, ora pela mera enunciação. De forma mais concreta, podemos pensar, em cada língua considerada sistema, nas diversas modalidades de pontuação ("i", ",", ":"); nas formas de modalizar, referir, explicitar (os "talvez", "provavelmente" e outros "ou seja" e "isto é"). Pensemos, ainda, nos parênteses, nas exclamações, reticências, bem como no leque tão colorido que a variedade lexical oferece para cada falante. De acordo com Derrida, é possível dizer que essa parafernália toda não é senão um processo incessante da língua para (se) expressar ao traduzir-se, uma agitação diligente e interna para correr atrás de uma significação e, quem sabe, de uma compreensão. Quanto àquilo que sustenta essa espécie de autoagressividade da língua, da língua esgotando-se, desmantelando-se e martirizando-se para dizer rumo ao outro sem deixar de dizer de si, Derrida indica um desejo, visando "a miragem de uma outra língua" (2016 [1996], p. 44, grifo meu).

Aqui, pergunto-me. Neste instante do Monolinguismo do outro, em que se encerra a tirada do desejo do monolíngue, a tradução em jogo constitui uma operação própria à língua, isto é, a tradução desobstrui, estica e faz a língua desabrochar sem sair da língua. Isso significa que, se os efeitos dessa tradução são efeitos intralinguísticos de objetivação, o "texto" aí produzido se produz sempre em uma língua relativamente uma, e que a tradução, por mais transformadora da língua que seja, não passa, nesse caso, de uma produção infra-linguística. Para formulá-lo nos termos da reflexão geral que nos anima, digamos que, enquanto uma coisa "traduzente" assombra a língua, empurrando o monolíngue para um fora do ente, parece que a língua, por sua parte, recupera a tradução, confinando-a em sua própria lógica. Quanto ao desejo por outra língua, desejo esse que tenciona a língua para o alhures que determinaria um para além dela, ele permanece finalmente "no horizonte", promessa adiada, visível, mas intocável.

É claro que as elaborações de Derrida a respeito da tradução não se reduzem a essa conclusão, como o veremos mais à frente. $\mathrm{O}$ filosofo, com efeito, deixou-se afetar de forma íntima por uma prática da tradução em línguas, se pudermos dizer assim, a fim de distinguir, por um lado, a práxis do tradutor e, por outro, a operação de tradução na língua, tal como entendida na perspectiva adoptada e genialmente performatizada no Monolinguismo do outro. Essa última perspectiva, que permite apreender um tipo de funcionamento imanente à língua sem recorrer à ciência linguística, visa destacar a tradução como anunciando uma assombração, através do testemunho singularmente intralinguístico de um monolíngue (inicialmente francófono) nos falando. Logo, para dar um passo a mais, é preciso reivindicar um "plus d'une langue" em que a visada desse "plus" configure, mais que uma promessa de língua "extra", uma experiência. 
Para tanto, cabe deslocar-se para outra perspectiva - sair um pouco mais doente! - e esforçar-se para articular a tradução à vivência multilíngue.

Fazer valer a aposta da tradução e... a tradução para valer!

\section{3. "PLUS D'UNE LANGUE, MAIS JAMAIS PLUS DE DEUX?" TRADUÇÃO E MULTILINGUISMO}

\subsection{Devolver a diversidade: aritmética do Um e do Dois}

"Comment 'rendre' l'effet de pluralité ?", perguntava Derrida em Des Tours de Babel? Como devolver e, simultaneamente, como dar a ver ou a ouvir o efeito de pluralidade? Do comentário estimulante e audacioso sobre A Tarefa do tradutor que ele arrisca, essa pergunta surge, tomando o tão assertivo e imperativo "Plus d'une langue" de surpresa. Devolver o efeito de pluralidade, e mais, devolver o efeito de diversidade enquanto pluralidade diferencial, significa que esse efeito é primeiro, e, logo, talvez a única dívida do tradutor diga respeito a essa multiplicidade. Ora, tal como tradicionalmente metaforizada ou, pior, modelizada, a tradução tende a trazer a pluralidade como diversidade de volta para a pluralidade como dualidade. Quando não convocando o Dois do contrato, sempre pensado entre duas partes, de acordo com o modelo do casal ou do casamento (o famoso pacto entre texto original e traduzido), apela-se ao Dois assimétrico, aquele do registro mais ético em que o falante, diante da alteridade absoluta da língua do Outro, deve "engolir sua língua" como se engoliria a dor ou o orgulho - para assumir uma responsabilidade totalmente desmedida. Ou então um dois com minúscula, o do acoplamento, por exemplo, com fundamento menos judaico-cristão e mais biológico ${ }^{12}$. Ou, ainda, o dois do par, como se bastasse calçar um par de línguas para poder traduzir, com um pé em cada uma das duas línguas, dançando bachata... Um - dois, um - dois, um - dois... e depois?

Assim analisada, a passagem obrigatória pelo "entre-duas-línguas" que defini e tentei mapear na introdução, esse intermédio confinante, nas palavras de Derrida, poderia muito bem ser chamado de impasse ou, pelo menos, interrogado como tal. Junto com nosso questionamento inicial, que inquire sobre a possibilidade de avançar além da zona de entre-duas-línguas, uma pergunta surge e diz respeito ao sentido que vamos dar ao "entre" da expressão. A primeira interpretação determina um tipo de relação dual e interlínguas; semanticamente, é o mesmo "entre" que o da língua

12. Todos esses Dois, diga-se de passagem, flertam perigosamente com o Um... 
francesa, o "between" do inglês. Além de postular uma relação ${ }^{13}$ potencialmente existente entre línguas, ela não dá conta da energia de transformação da tradução. Ademais, como se não bastasse, poderia ser prontamente desmascarada como tentativa - metafísica sem saber - para voltar ao Um do único e do imutável. Um ersatz de diversidade, em suma.

A segunda interpretação entende o "entre línguas" como um plano de imanência - "among" languages, "parmi" les langues -, resgatando a diversidade quente e dinâmica contra a dualidade congelada suposta pelo "between". Em certa medida, é esse tipo de resgate que o escritor e filosofo martinicano Édouard Glissant propõe, quando define e reivindica, em Introduction à une Poétique du Divers, um multilinguismo radical que poderia ser chamado de "entre-todas-as-línguas", em um sentido muito preciso. Citando Glissant:

"Falo e, sobretudo, escrevo na presença de todas as línguas do mundo". (GLISSANT, 1996, p. 39)

e, logo depois:

"Repito que o multilinguismo não supõe a coexistência das línguas nem o conhecimento de várias línguas, mas a presença das línguas do mundo na prática da sua; é aquilo que chamo de multilinguismo". (GLISSANT, 1996, p. 41)

\subsection{Dar a ver a diversidade: uma epifania prática}

À luz da citação anterior, não é preciso dizer que, da mesma forma que o monolinguismo do outro testemunhado por Derrida é dificilmente concebível sem sair das categorias da Linguística, o multilinguismo de Glissant (um monolinguismo do tudo?) também escapa à definição costumeira e/ou linguística de multilinguismo. Não se trata de ter domínio teórico, efetivo ou não ("conhecer") em várias línguas. Mas tampouco remete a um sentido frouxo do "entre-as-línguas", do tipo descritivo: "existem várias línguas". And so what? Nem habilidades individuais para diversas línguas, nem mera constatação da sua diversidade, em Glissant, o multilinguismo engaja uma prática, principalmente a escrita.

Escrever, nesse sentido, é uma forma privilegiada de dar a ver a diversidade que jaz no mundo, sem voz. Escrevo em uma língua que uso - e, a bem da verdade, escrevo para a língua, no sentido em que a escrita visa a "construção de uma

13. Esse postulado será examinado mais adiante, e explicitarei o sentido exato que dou ao termo "relação". 
linguagem" (GLISSANT, 1996, p.42) - mas essa língua carrega traços das outras línguas escritas, faladas e possíveis do mundo. Quase uma tradução em forma de funil! Passo (de) todas as línguas do mundo para uma "relação para com as palavras" inédita, a própria prática de escrita na minha língua operando como tradução. A cada vez que um escritor ou um poeta escreve, a diversidade habitualmente recoberta pela propensão ao monolinguismo aparece: as outras línguas estão aqui ${ }^{14}$.

O poeta, de acordo com uma linda metáfora de Glissant, erra, trilhando seu caminho ao atravessar uma densidade múltipla de línguas, como se atravessasse "matagais de línguas" (GLISSANT, 1996, p.114). "As outras línguas estão ali", afirma e testemunha Glissant; foram atravessadas e devem ser repassadas a cada momento. Atravessar a língua crioula da Martinica, como se atravessa um eco, uma lembrança longínqua dos contadores de histórias da infância. Atravessar, também, outros crioulos, eles totalmente herméticos, como se anda no escuro, sem encontrar sentido. Atravessar o francês, que se apresentou pela influência escolar das poéticas de Rimbaud e Mallarmé, e, por isso, operar um trabalho autorreflexivo. Finalmente, atravessar uma presença, a do inglês da obra de Faulkner. Édouard, Deslizando... Assim, entendemos que o tipo de epifania das línguas praticada pelo escritor é o desdobramento, pelo gesto literário, de uma trajetória singularmente vivenciada de encontros e embates com línguas: escreve-se raspando-se, parece nos dizer Glissant, faz-se literatura através de matagais que atravessamos e reatravessamos a corta-mato; medindo-se e esfolando-se com as línguas do mundo.

Então, por que não chamar essa trajetória, também, de "tradução", no sentido do processo-acontecimento de um autor que se daria não entre duas linguas, mas, antes, por entre várias línguas?

Mas e a prática da tradução, a tradução como prática, no seu sentido mais estreito? Qual o estatuto que ela tem nessa grande diversidade feita de todas as travessias de todas as línguas do "Tudo-mundo"15? Cabe perguntar-se, porque se tudo é tradução, nada é tradução!

14. No momento em que avança essa afirmação, Glissant cita o exemplo dos últimos textos de Joyce, Anna Livia Plurabelle, entre outros. Seria interessante examinar o caso de Joyce, igualmente crucial em Derrida, que a ele dedicou o extraordinário ensaio Ulysse gramophone. Deux mots pour Joyce, e em Lacan, que se aproxima da escrita joyciana no livro XXIII do seminário, Joyce le Symptôme. Perguntome, em especial, se as línguas coexistem no modo da copresença em Joyce, ou se não haveria, mais violentamente, um tipo de guerra (He war) entre elas, ou até mesmo um trabalho para levar a língua inglesa ao seu cabo (um tipo de auto-esgotamento do inglês).

15. Título de uma obra do Glissant escritor, cuja leitura é eminentemente recomendável a quem quiser adentrar a rede das línguas do mundo, atravessando os matagais com Glissant. 


\subsection{A tradução como crioulização: uma arte da fuga}

Ainda na mesma Introduction à une Poétique du Divers, encontramos elementos extremamente entusiastas sobre a arte do tradutor e a tradução stricto sensu, anunciada por Glissant como uma "das [mais importantes] artes do futuro" (1996, p.45):

\footnotetext{
"o tradutor inventa uma linguagem necessária de uma língua à outra, como o poeta inventa uma linguagem na sua própria língua. Uma língua necessária de uma língua à outra, uma linguagem comum às duas, mas, de alguma maneira, imprevisível em relação a cada uma. A linguagem do tradutor opera como a crioulização [...] ou seja, essa linguagem é produção de imprevisível. Arte do imaginário, nesse sentido, a tradução é uma verdadeira operação de crioulização, prática agora nova e imparável da preciosa mestiçagem cultural" (GLISSANT, 1996, p. 45, grifos meus)
}

Vemo-nos, aqui, diante de uma oscilação interessante. Por um lado, uma analogia é proposta entre "crioulização" e o modo como a linguagem do tradutor opera. Por outro lado, a tradução é uma "verdadeira" operação de crioulização. Vejamos bem: a crioulização, em Glissant, não significa (apenas) o fato sóciohistórico de tornar-se ou assumir-se "crioulo", menos ainda o fato de falar uma língua dita crioula. Tampouco significa incorporar - enfiar, sempre de forma mais ou menos arbitrária e violenta - o léxico de uma língua minoritária em uma língua considerada dominante, e reivindicar isso como uma poética. Ao invés, a crioulização nomeia o processo imprevisivel pelo qual "elementos heterogêneos" relacionados entre si "se intervalorizam" (GLISSANT, 1996, p.25), e esse imprevisível é o valor acrescentado da crioulização em comparação com a mestiçagem. Uma operatividade contingente com a qual se parece o gesto do tradutor, que faz emergir uma linguagem nova, como uma conexão ${ }^{16}$ inédita, e à qual a prática da tradução, "arte da vertigem [...] errância salutar", é essencialmente remetida.

A tradução, ali, define-se como uma atividade de (trâns)fuga, ao mesmo tempo escapando e respondendo por uma potência crioulizante. Isso tem implicações gnoseológicas que dizem respeito a sua redefinição e à compreensão de seus efeitos: é "uma espécie entre as mais importantes [do] novo pensamento arquipelágico" (1996, p.25) ao qual Glissant apela. Em última análise, poderíamos dizer que a implicação derradeira da tradução é cosmogônica: criação de um mundo novo, pela reconfiguração das relações entre os elementos do mundo que ela instaura. E, de fato, é forçoso constatar que, na tradução e, sobretudo, pelo gestolinguagem do tradutor, a dimensão do imprevisível é primordial. Não somente a boa

16. Com a noção de "conexão", remito ao trabalho do antropólogo e etnólogo Jean-Loup Amstelle (2001), que propõe a passagem da noção de "métissage" (mestiçagem) para a noção de "branchement" (conexão, ramificação). 
tradução surpreende, criando espanto. Mas os resultados da tradução não podem ser previstos antes de ela operar em vista da produção de uma linguagem, produção essa que alimenta uma diversidade viva, vivaz e "não binária" (da qual nenhum algoritmo nunca dará conta). Nessa diversidade, e na linguagem dessa diversidade que a tradução faz advir, "todos os possíveis, todas as contradições são inscritos" (GLISSANT, 1996, p. 25). Tradução: presença das línguas; abertura aos possíveis e contradições muito bem-vindas.

Mas então, se a tradução aparece, agora, como uma chave da crioulização e um elemento integrante do gesto literário em um sentido amplo, se ela nos dá a viajar, trilhando seu processo no coração de um mundo de línguas que ela coloca em presença com-juntas - uma ecoando em outra, outra potencializando ainda outra, supervalorizando suas características próprias sem por isso deixar de render suas ressonâncias próprias - essa ampliação da Diversidade do mundo tal como concebida por Glissant não seria o signo do grande Desconfinamento que buscávamos? Sim, e não. Apesar de falar da arte da tradução em termos de "passagem [...] de uma [língua] à outra" (GLISSANT, 1996, p.45) ou, ainda, de "quase toque" [effleurement] e "aproximação" [approche] (p.46), em outro nível que poderíamos chamar de macroteórico, Glissant vai muito mais longe. A intuição genial segundo a qual "cada tradução, hoje, acompanha a rede de todas as traduções possíveis de toda língua em toda língua" (p.46) configura uma rede rizomática ${ }^{17}$ atualizando, a cada momento, a complexidade e o processo de transformação inerente a línguas todas virtualmente em tradução.

Portanto, à constatação-convocação "As línguas estão aqui", haveria de acrescentar: "As traduçôes estão aqui".

\section{TRADUZIR, TRANSBORDAR, TRANS-ART. ENCORE PLUS DE LANGUES!}

\subsection{De uma "não-relação" entre as línguas... e a tradução, então?}

Língua entre línguas, tradução entre traduções, lascas de mundo e até mesmo mundos possíveis estariam contidos, entrelaçados, na invenção de linguagem que cada tradutor inaugura. Contudo, enquanto não são tantos os tradutores que se esforçam para encontrar a forma de dar a ver/devolver a produção de diversidade potencializada pela sua prática (isto é, em certa medida, a potência transcriativa do

17. Uso um adjetivo deuleuziano, que o próprio Glissant não recusa (cf. "L'"écrivain et le souffle du lieu", ainda em Introduction à une Poétique du Divers). 
seu gesto ${ }^{18}$ ), a tradução como invenção de uma linguagem e, logo, como produção de novidade tornando propícia uma circulação através das línguas supõe um ato totalmente original, na estrutura do qual o próprio tradutor se encontra tomado e transformado. E esse ato, por sua vez, nunca "está aqui", mas precisa ser assumido, efeituado e arriscado, sempre de maneira inédita.

Nesse sentido, tendo a pensar que a energia desconfinante ligada à prática da tradução que buscamos se encontra, caso a caso, na análise das ousadias dos tradutores; nas escolhas de tradução, mas sobretudo na tradução como escolha bancada. Tal dimensão se dá em um ponto muito específico, que não é o entre do entre-línguas, concebido como um lugar comum às línguas (um tipo de zona neutra) ou compartilhável entre elas (uma zona franca), mas que tampouco se dá no grande Entre que Glissant teoriza e que Alpha Blondy canta ${ }^{19}$ e no qual as línguas teriam Relação com respeito e amor (fantasia de uma espécie de território universalmente acolhedor, reino utópico da reconciliação de todas as línguas cujo risco é alimentar a tendência à negação do mal-entendido e da conflitualidade latente entre-línguas). Trata-se, antes, de um tipo de lugar nenbum, ponto de heterogeneidade radical entre as línguas em que, justamente pela ausência radical de relação entre as línguas, isto é pensando, em francês e depois de Lacan, a relação como "rapport" - pela ausência primordial de ligação (junção permitindo a comunicação) e de rácio (compatibilidade ou proporcionalidade) um tradutor deve passar ao ato de tradução.

Destarte, se almejamos conceber esse lugar nenhum, em que a exterioridade de algo da ordem do "fora-língua" se materializa, de forma contingente e determinante, para que seja feita tradução, esse conceber não depende apenas de um esforço de elaboração teórica. Quem torna a porta "abrível", aplicando uma dobradiça singular num acesso sem estrutura prévia, para depois autorizar sem dizer: "Entre! 20" ("Passe!"; "faça contato!") são os tradutores. Cada um, cada uma com seu estilo, faz da não-relação inaugural entre as diversas línguas uma vasta "arte (do) trans-". Essa arte, chamamo-la por uma locução, ou melhor, por uma loucução à altura do risco em jogo: é a tradução como Trans-art! E o desafio não consiste mais, neste ponto, em descobrir "comment les langues s'entendent" (Glissant, 1996, p. 44) - como as línguas se ouvem, se escutam e se dão (bem ou mal) entre

18. Sobre transcrição, cf. a obra Haroldo de Campos - Transcriação (2013).

19. Cf. a epígrafe deste trabalho e nota 1. Para uma re-escuta, ao vivo, da mesma música - com um tipo de hino ao sincretismo inédito preludiando à versão reggae da explosão babélica a partir de 2’40 (grito da bateria + pulos e giros do bardo) - , ouçam e vejam: https://www.youtube.com/ watch?v=YzLA_AaxjLs

20. Uma linda meditação sobre o "Entre" como imperativo é proposta por Barbara Cassin no final de seu Éloge de la traduction. 
elas - mas em mostrar como um tradutor, ao atravessar a provação da tradução, transpassa a ordem estrancilhada da literalidade pura para propor um texto legível. Em outras palavras, nossa pergunta inicial acaba deslocando-se, transfigurando-se em outra mais relevante: como tradutores-passadores, "forçando a barra" do entreduas-línguas, podem nos transmitir - apesar e a partir dessa barreira - um texto paradoxalmente inédito?

\subsection{Tradutores, passadores e passantes: a relève da tradução evocada a partir de dois casos}

"Plus d'une langue", repete Derrida. "Maquis de langues", escrevia Glissant. "E se traduzirmos por várias línguas de uma vez, chamar-se-á aquilo de traduzir?" (Derrida, 1998 [1987], p. 208). "[A questão] não é a justaposição das línguas, mas sua colocação em rede [em francês: mise en réseau] (Glissant, 1996, p.123). Last but not least, Derrida novamente, no extraordinário texto "Qu'est ce qu'une traduction "relevante?" (2004), falando precisamente da estranheza da palavra "relevante", que constitui também o achado de um quase-tradutor:

[S]i j’ai pris l'initiative de ces quasi-traductions, je n'ai pu le faire qu'à écouter, pour les enregistrer, des possibilités ou des lois - sémantiques et formelles - déjà inscrites dans cette famille de langues, en premier lieu dans « ma » langue.

$[\ldots]$

Au commencement de la traduction, il y a le mot.

[S] tomei a iniciativa dessa quase-traduções, pude apenas fazê-lo ao escutar, para registrá-las, possibilidades ou leis - semânticas e formais - já inscritas nessa família de línguas, em primeiro lugar na "minha" língua.

$[\ldots]$

No início da tradução, bá a palavra. (DERRIDA, 2004, grifos meus, p. 563-564).

Primazia da colocação em rede na tradução, ou prática da quase-tradução a fim de dar vantagem à palavra? Invenção de uma linguagem para ligar línguas em tradução ou criação de um significante que já está, essencialmente, traduzintetraduzindo-se ("relevante" oscila, por si só, entre francês, inglês, tradução do alemão para o francês, português...)? Neste ponto, vemos que, apesar de semelhanças, as propostas de Derrida e de Glissant diferenciam-se quando se trata de voltar aos fundamentos da tradução. Seria interessante, em outra ocasião, aprofundar essa diferença do ponto de vista dos estudos da tradução, pois ela implica em modalidades do fazer-tradução bem distintas. Tão somente, evocarei - en repassant - dois casos de invenções, particularmente importantes, a meu ver, na medida em que inventam não somente correspondências entre línguas e diálogos intertextuais, 
mas operam com tradução além dos limites da tradução - isto é, dos contratos e dos ritos de tradução.

No início, uma dificuldade. Como traduzir Glissant sem trair a determinação glissantiana da tradução acima destacada: "As línguas estão aqui", à qual acrescentei "As traduções estão aqui"? Uma tradução que seria executada de forma acadêmica, atendo-se a trazer ou deslocar Glissant em/para um outro idioma, estimularia a circulação das ideias do autor, o qual alcançaria um público maior. Só por isso, já valeria a pena; essa tradução teria sua legitimidade. Contudo, talvez possamos imaginar outra forma, uma forma menos normatizada de transmissão - e que teria a desvantagem de chegar a menos leitores - forma essa que permitiria não apenas deslocar Glissant, mas atualizar a concepção glissantiana da tradução como parte do pensamento arquipelágico. Eis a audácia que o tradutor e teórico da tradução Giuseppe Sofo realiza no seu artigo "L'Archipel de la traduction. Glissant au prisme de la traduction, la traduction au prisme de Glissant" (2020). Nele, trechos traduzidos, notas e marcas de traduções, elas mesmas traduzidas pelo autor, se entrelaçam em francês, alemão, inglês e, ainda, em italiano, constituindo-se em rede de traduções e oferecendo ao leitor uma forma privilegiada de apreender o pensamento arquipelágico de Glissant: "uma leitura plurilíngue, isto é 'em presença de todas as línguas" (SOFO, 2020). Aqui, a escolha de manter a dimensão do "outras" (das outras línguas, que não são consideradas como propriamente estrangeiras) no corpo do texto é o modo de produzir uma reflexão sobre as traduções de Glissant à altura do pensamento de Glissant, o tradutor-autor do artigo sendo, dessas traduções e pensamento, um verdadeiro passador.

Com o mesmo intuito de passar, mas de forma diferente - provavelmente mais radical (digamos, mais mulher!) - a tradutora Viviane Veras, em seu texto "Uma tradução bem temperada: uma resposta a Jacques Derrida", propõe um texto bien relevé, picante e apetitoso. Dizer que se trata, para ela, de "relever" Derrida, operando a partir desse verbo polissêmico depois do próprio Derrida, não significa somente que ela distingue (relève) as especificidades objetivas da proposta derridiana, mas que ela destaca essa proposta para erguê-la novamente (re-lever), chegando, como chega um novo turno, para assumir o comando (prendre la relève) de um pensamento da tradução baseado no sabor das palavras; un gusto!

Vejamos um trecho em que, traduzindo e reiterando uma pergunta derridiana que julgamos absolutamente incontornável, Veras aproveita o "passeio entre línguas, oferecendo lugar a mais uma língua - [a] língua brasileira" (VERAS, texto inédito), como que perguntando-se para ela mesma e, no fundo, para todos os tradutores: 


\begin{abstract}
"Minba operação foi uma tradução?" Derrida pergunta. Seria mais, ele diz, mais uma dessas "coisas em $\operatorname{tr}^{\prime \prime}$, uma transação, transformação, um trabalho transferencial, um trabalho de parto, e, acrescento, um trabalho de trovador, de ambulante entre línguas, "que descobre o que estava nelas adormecido" para pô-lo para trabalhar além das fronteiras, além da morte. Um desafio a mais, acrescenta, "a toda tradução que gostaria de acolher em uma outra língua todas as conotações que vêm se acumular nessa palavra". E que faça trabalhar as línguas sem adequação nem transparência, simulando uma nova escrita, como, ouso dizer, um trabalho do sonho, que atravessa as palavras-pontes no livro de Freud, verdadeiros pontos de fuga entre línguas adormecidas à espera de um fazer escutar o seu acorde. (VERAS, texto inédito)
\end{abstract}

"Minba operação foi uma tradução?" Pergunta lancinante, relevada por Veras e que também pode se aplicar ao seu próprio texto, para interrogar algo - um produto textual - que transborda alegremente a prática da tradução bem como a de explicação de texto, sem deixar (muito pelo contrário) de produzir efeitos tradutórios e explicativos. Pergunta ímpar, também, na medida em que ela abre caminho para pensar uma operação que envolve a dimensão do traduzir, sem reduzirse ao campo balizado pelas normas acadêmicas, institucionais e/ou mercantis. Aí, as línguas entram em vibração [trrrrrrr], junto com as identificações. O leitor acorda! O que é isso?? Achamos que uma tradutora escreve? Lemos uma tradução de Veras? De repente, o comentário de uma leitora entusiasta surge, pensando-escrevendo em voz alta e trazendo na roda ora o Gil, ora o Freud: é a Vivi que fala. E nessa espécie de mais-de-tradução, algo passa, que tem a ver não somente com um acontecimento de texto, mas também com uma transformação ou, pelo menos, uma transição identitária. Os giros da tradução produzem, por fim, uma mulber, a saber, um (traduz) ente multifacetado que designa, como diz Cassin na sua correspondência com Alain Badiou, "um processo [mais do que] uma posição - uma passante" (2019, p.77).

Mas então, mesmo que não se possa estreitamente categorizar um tal processo, como poderíamos nomear o produto textual que resta do acontecimento que, além de materializar efeitos de tradução, produz efeitos notáveis de transposições identitárias? Cabe lembrar, aqui, que um termo já existe para qualificar uma operação que se aproxima da tradução: o termo paratradução, forjado pelos estudiosos das condições de transmissibilidade de um texto traduzido com base na noção de "paratexte" cunhada por Gérard Genette. Nesse cenário:

A noção de paratradução, ao invitar a refletir, vem destacar uma nova perspectiva, fiel à etimologia e ao sentido do prefixo para, sobre o que acontece na margem do processo tradutório ou, mais precisamente, no limiar da tradução (YUSTE FRÍAS, 2010).

Não é isso, aqui, que busco relevar. Atenta a uma operação diferente tanto da tradução - apesar de passar (por) ela - quanto da paratradução - ainda que resgatada, várias vezes, por ela - proponho, como resultado da reflexão desenvolvida 
neste artigo, o termo de transtradução. Com cuidado, porque o prefixo trans- também poderia ecoar uma noção genettiana - a de "transtextualidade" - mas não é nesse sentido que sugiro escutá-lo. Ele será muito mais felizmente entendido, aqui, em consonância com "transgressão", "transtornar", e até mesmo com "transgênero".

Com efeito, se o paratradutor, nas margens do texto, garante a recepção de um texto, isto é, se ele assegura e se responsabiliza por sua sobrevivência como objeto oferecido a ler dentro de um quadro relativamente estruturado, identificável e reconhecido pelos profissionais do texto (revisores, editores, avaliadores...), o transtradutor, por sua vez, tende frequentemente a ficar nos limbos da publicação, quando não votado à rejeição pura e simples pelos mesmos profissionais. À semelhança do transcriador, ele anda sem garantia alguma para originar resultados bizarros, mas também particularmente excitantes, marcados por uma assinatura e um desejo absolutamente singulares. Porém, nesse andar desandando, ele dá um passo a mais, que tem a ver com o mergulho babélico gozado enquanto tal. Pouco preocupado com o horizonte de criação, no sentido de um fazer-obra, o transtradutor transborda, desliza, debocha e escapa das estruturas já prontas, burlando as leis de tradução ao mesmo tempo em que borra escandalosamente as fronteiras idiomáticas. Nesse sentido, longe de ser tautológica ou trivialmente redundante, a replicação do prefixo "trans-" evidentemente identificável no termo de "transtradução" 21 busca denominar o efeito de excesso - quase da ordem de uma pulsão de tradução - pelo qual a primazia de um mais-de-traduzir sobre qualquer a-traduzir é externada, tornada legível. A transtradução, em última instância, é mostração: apresentação monstruosa da necessidade imperiosa que vigora para além do entre-duas-línguas.

\section{CAIR FORA! UM ATO DE TRANSTRADUÇÃO?}

E eu, então, chegando a termo desta reflexão... que forma poderia inventar? Ou que forma deveria intentar, se é verdade que, na forçagem do limite do entre-duaslínguas, é o tradutor que há de (se) reinventar?

Se uma tradução acaba quando aquele que traduz põe um ponto final à sua tradução, alguma coisa, por trás, fica esquecida. Uma coisa traduzente da qual podemos dizer, parafraseando a definição do real em Lacan, que ela não para de (não) se traduzir. Ora, para sugerir esse real da tradução que não cessa de não se inscrever sob a forma de uma tradução a-ler (e há uma infinidade de formas, tantas

21. Pois implicitamente, o termo "tradução", em virtude da sua etimologia, já contém um primeiro "trans-". 
formas quantos atos de tradutoras e tradutores), concluir este artigo, como seria de bom tom agora, não é uma opção. Para levantar um bocadinho de recalque, nem apenas uma tradução do meu próprio texto (dita autotradução) bastaria, pois, apesar da complexidade de traduzir um texto tecido em "mais de uma língua", seriamos reconduzidos a um esquema geral funcionando a partir do postulado da bilateralidade das línguas entre si. A saída que enxergo, para desconfinar-me, finalmente, do meu próprio texto, exigiria uma transgressão. "Romper os tratados" e "trair os ritos"... do artigo científico.

Portanto, sem transição nem conclusão, continuaria e recomeçaria anunciando outro artigo, mais um artigo, mais de um artigo. Não uma paratradução, e mais que uma tradução; uma transtradução. Dela, pois, resultaria um transtexto em que outras línguas, repentinamente, sem pedir permissão, fariam irrupção. Sobretudo, a transtradução produziria uma assinatura inédita - um heterônimo potente - capaz de relevar a prática confinante da autotradução apostando, além do "plus d'une langue" de Derrida, na tradução em "um monte de línguas"!

"Marie-Lost In Translation"? Pode ser..

$\mathrm{Ou}$ :

"Thérèsa Mariette O'Arroz Cana"? Translinguisticamente mais prometedor, com certeza. E, brincando de anagramas com as maiúsculas:

C. TOA, ou

C. MOA....?

É você - c'est toi - que traduz, ou eu - c'est moi -, transtraduzida?

\section{Finalement(e):}

«Plus d'une langue », et « encore plus de langues ? » c Qué tal ? Et pourquoi pas convoquer un tas de langues, «Plein de langues». Faire le plein de langues; like Refueling linguages... Entre saturation et excès, il s'agirait de mettre en œuvre un « toujours plus de langues » pour évaluer les risques mais aussi les bonheurs, en traduction et ailleurs, d'un éventuel trop-plein de langues... « Full of linguages : Translation for even more deconfinement »!

Yallah!

\section{REFERÊNCIAS}

AMSELLE, J-L. (2001). Branchements. Antbropologie de l'universalité des cultures. Paris: Flammarion.

BADIOU, A.; CASSIN, B. (2019). Homme, femme, philosophie. Paris: Fayard. 
CAMPOS, H. de. (2013). Haroldo de Campos - Transcriação. TÁPIA, M.; NÓBREGA, T. M. (orgs.). São Paulo: Perspectiva.

CASSIN, B. (dir.). ([2004] 2019). Vocabulaire européen des pbilosopbies - le Dictionnaire des intraduisibles (édition augmentée). Paris: Seuil.

CASSIN, B. (dir.). SANTORO, F.; BUARQUE, L. (org.). (2018). Dicionário dos intraduzíveis. Um vocabulário das filosofias. Belo Horizonte: Autêntica Editora.

CASSIN, B. (2014). Philosopher en langues. Les intraduisibles en traduction. Paris: Éditions de la Rue d'Ulm.

CASSIN, B. (2016). Éloge de la traduction: compliquer lıniversel. Paris: Fayard.

DERRIDA, J. (1987). Ulysse gramophone. Deux mots pour Joyce. Paris: Galilée.

DERRIDA, J. (1988). Mémoires pour Paul de Man. Paris: Galilée.

DERRIDA, J. ([1996] 2016). Le Monolinguisme de l'autre. Ou la prothèse d’origine. Paris: Galilée.

DERRIDA, J. (1998). «Des tours de Babel ». Psyché. Inventions de l'autre. Paris: Galilée.

DERRIDA, J. (2004). «Qu'est-ce qu'une traduction "relevante" ? » Paris: Cahier de l'Herne.

GLISSANT, É. (1996). Introduction à une poétique du divers. Paris: Gallimard.

LARANJEIRA, M. (2012). Sentido e significância na tradução poética. Estudos Avançados, 26(76), 29-37. Disponível em http://www.revistas.usp.br/eav/article/view/47536 Acesso em: 12 de junho de 2020.

LEITE, N. V. de A.; SOUZA Jr., P. S. (2020). Corpo e língua materna. Revista Cult. v. 2 "Corpo", artigo no prelo, publicação prevista para o segundo semestre de 2020.

NOUSS, A. (2012). A tradução: no limiar. Trad. Tradução de Izabela Leal. Alea. v. 14/1.

SOFO, G. (2020). L'Archipel de la traduction. Glissant au prisme de la traduction, la traduction au prisme de Glissant. Revue TRANS-. v. 25 - "Insularités/Archipels". Disponível em: https://journals.openedition.org/trans/3379. Acesso em: 12 de junho de 2020 .

VERAS, V. "Uma tradução bem temperada: uma resposta a Jacques Derrida". Texto inédito. 
YUSTE FRÍAS, J. (2010). «Au seuil de la traduction : la paratraduction ». Naaijkens, T. [ed.] Event or Incident. Événement ou Incident. On the Role of Translation in the Dynamics of Cultural Exchange. Du rôle des traductions dans les processus d'échanges culturels, Bern, Berlin, Bruxelles, Frankfurt am Main, New York, Oxford, Wien : Peter Lang, col. Genèses de Textes-Textgenesen (Françoise Lartillot [dir.]). v. 3.

Recebido: $22 / 6 / 2020$

Aceito: $17 / 7 / 2020$

Publicado: 24/7/2020 